\title{
PENGEMBANGAN BUKU PENGAYAAN KIMIA BERORIENTASI ETNOSAINS KAMPUNG SETU BABAKAN DKI JAKARTA
}

\author{
Muhammad Rusdil Fikri ${ }^{{ }^{*}}$, Burhanudin Milama $^{\mathbf{1}}$ dan Luki Yunita \\ ${ }^{1}$ Program Studi Pendidikan Kimia, Fakultas Ilmu Tarbiyah dan Keguruan, UIN Syarif \\ Hidayatullah Jakarta, \\ Jl. Ir H Juanda, No. 95, Ciputat, Tangerang Selatan 15412, Indonesia \\ *E-mail: rusdil.fikri14@mhs.uinjkt.ac.id
}

\begin{abstract}
ABSTRAK
Keberagaman budaya asli tiap daerah belum dimaksimalkan dalam pembelajaran kimia di sekolah menengah atas pada daerah masing-masing. Belum banyak buku pengayaan kimia yang mengaitkan konsep dengan konten informasi kebudayaan lokal. Tujuan dari penelitian ini untuk menghasilkan buku pengayaan berorientasi etnosains kebudayaan lokal Kampung Setu Babakan DKI Jakarta, mengetahui karakteristik buku dan mengetahui respon siswa dan guru terhadap buku. Metode penelitian mengembangkan model ADDIE yang memiliki lima tahap yaitu analisis, desain, pengembangan, implementasi, dan evaluasi. Teknik pengumpulan data yang digunakan yaitu wawancara, validasi, dan angket menggunakan skala Likert. Data yang diperoleh dari hasil penelitian menjadi dua kelompok yakni data kuantitatif dan data kualitatif dengan teknik pengolahan data yaitu validasi buku dan data angket respon, kemudian analisis data menggunakan skala Likert dan interprestasi skor. Hasil penelitian tiap tahapan yang diperoleh yaitu: pada tahap analisis diperoleh kesenjangan kinerja untuk mencari informasi agar masalah yang diteliti memiliki kedudukan yang jelas, pada tahap desain diperoleh hasil verifikasi kinerja dan keterkaitan etnosains dengan materi kimia, pada tahap pengembangan diperoleh buku yang telah divalidasi oleh satu orang ahli media, satu orang ahli kimia, dan satu orang guru bidang studi kimia, pada tahap implementasi buku pengayaan dilakukan uji coba terbatas dan diperoleh data hasil respon dari empat orang guru kimia dan 35 siswa kelas XII MIPA 4 SMAN 38 Jakarta, tahap evaluasi dilakukan pada setiap tahap sebelumnya. Kemudian hasil penelitian dari angket respon guru dan siswa terhadap buku dihasilkan $87 \%$ untuk guru dan $84,20 \%$ untuk siswa dengan kategori sangat baik dan layak untuk digunakan pada pembelajaran di sekolah menengah atas. Karakteristik buku juga telah memenuhi beberapa kriteria yaitu materi, penyajian, bahasa, dan kegrafisan sehingga termasuk kategori sangat baik, karena itu, buku pengayaan dapat digunakan sebagai bahan ajar tambahan untuk sekolah menengah atas di DKI Jakarta.
\end{abstract}

Kata Kunci: $A D D I E$, buku pengayaan, etnosains, kampung setu babakan 


\section{ABSTRACT}

The diversity of indigenous cultures of each region has not been maximized in chemistry learning in upper secondary schools in their respective regions. There are not many chemical enrichment books that link concepts with information content on local culture. The purpose of this study was to produce an enrichment book oriented to the ethnics of local culture in Kampung Setu Babakan DKI Jakarta, to know the characteristics of the book and to find out the responses of students and teachers to books. The research method of developing the ADDIE model has five stages, namely analysis, design, development, implementation, and evaluation. Data collection techniques used are interviews, validation, and questionnaires using a Likert scale. Data obtained from the results of the study into two groups, namely quantitative data and qualitative data with data processing techniques, namely book validation and response questionnaire data and then data analysis using a Likert scale and interpretation of scoring. The results of the research for each stage obtained are: in the analysis phase, the performance gap is obtained to find information so that the problems studied have a clear position, at the design stage the results of verification of performance are obtained, at the development stage a book was validated by one media expert, one chemist, and one chemistry study teacher, at the stage of implementation of the enrichment book a limited trial was conducted and data obtained from the response results from four chemistry teachers and 35 students of class XII MIPA 4 SMAN 38 Jakarta, the evaluation stage is carried out in each of the previous stages. Then the results of the study of teacher and student responses to the questionnaire produced $87 \%$ for teachers and $84,20 \%$ for students with very good and appropriate categories for use in high school learning. The characteristics of the book also meet several criteria, namely material, presentation, language, and graphics so that it includes a very good category therefore, enrichment books can be used as additional teaching materials for high schools in DKI Jakarta.

Keywords: ADDIE, enrichment books, etnosains, setu babakan village

DOI: https://doi.org/10.15575/jtk.v4i2.4546

\section{PENDAHULUAN}

Dalam pelaksanaan kurikulum di Indonesia, kurikulum telah mengalami beberapa kali perubahan, mulai dari kurikulum sederhana hingga kurikulum 2013 yang saat ini mulai diterapkan, kurikulum 2013 memiliki 7 karakteristik. Jika ditelaah lebih lanjut mengenai karakteristik nomor 1 sampai 3 dapat ditarik kesimpulan bahwa kurikulum 2013 menuntut siswa untuk mengimplementasikan hasil pembelajaran yang mereka dapat di sekolah kepada masyarakat (Permendikbud No. 70 Tahun 2013). Suastra (2006) menyatakan bahwa kurikulum berperan sebagai media dalam mengembangkan kebudayaan daerah, nasional, dan global. Sehingga kurikulum memberikan kesempatan kepada peserta didik untuk belajar dari budaya setempat dan nasional tentang berbagai nilai yang penting dan memberikan kesempatan untuk berpartisipasi serta mengembangkan nilainilai budaya setempat dan nasional menjadi nilai budaya yang digunakan dalam kehidupan sehari-hari.

Mengacu pada hal tersebut, menurut Sudarmin (2014) amanat dan prinsip pengembangan dari kurikulum sains 2013 yang saat ini berlaku yaitu memperhatikan budaya lokal sebagai sumber belajar sains dan menginternasionalkan budaya lokal. Salah satu caranya adalah menyajikan sumber belajar dengan merekonstruksi pengetahuan 
Pengembangan Buku Pengayaan Kimia Berorientasi Etnosains Kampung Setu Babakan DKI Jakarta

sains ilmiah yang berorientasi budaya atau etnosains.

Shidiq (2016) dalam penelitiannya menyatakan bahwa dengan etnosains siswa tidak memandang sains sebagai suatu budaya asing yang mereka pelajari, tetapi dipandang sebagai bagian dari budaya dan kearifan lokal yang ada. Hal tersebut didukung oleh hasil penelitian yang dilakukan oleh Kartono dkk. (2010) yang menyatakan pendidikan sains dapat dikembangkan dengan bertumpu pada keunikan dan keunggulan suatu daerah, termasuk budaya dan teknologi lokal (tradisional). Battiste (2005) menyatakan etnosains juga suatu kajian dari sistem pengetahuan asli dari budaya masyarakat dan fenomena yang berhubungan dengan alam semesta yang terdapat di masyarakat lokal. Pembelajaran yang mengimplementasikan tradisi budaya lokal mampu menghantarkan siswa untuk mencintai daerah dan bangsanya. Sejalan dengan pendapat Yuli Rahmawati (2017) bahwa etnosains merupakan cara baru melihat budaya dari perspektif ilmiah. Sehingga dapat ditarik kesimpulan bahwa budaya asli daerah nya juga dapat menjadi motivasi peserta didik dalam memahami dan mempelajari ilmu-ilmu sains.

Keberadaan bahan ajar merupakan faktor penting dalam menunjang keberhasilan pembelajaran, disebabkan bahan ajar dapat menghubungkan, bahkan dapat memadukan antara pengalaman dan pengetahuan peserta didik (Toharudin dkk., 2011). Bahan ajar selain buku teks yang dapat dikembangkan oleh guru sebagai salah satu sumber belajar adalah buku nonteks. Buku nonteks pelajaran adalah buku-buku berisi materi pendukung, pelengkap, dan penunjang buku teks pelajaran yang memiliki fungsi sebagai bahan pengayaan, referensi, atau panduan bagi peserta didik serta guru dalam kegiatan pendidikan dan pembelajaran. Bentuk penyajian pada buku nonteks yang longgar, kreatif, dan inovatif dapat pula dimanfaatkan oleh pembaca lintas jenjang dan tingkatan kelas atau pembaca umum dan beberapa buku yang termasuk ke dalam buku nonteks pelajaran adalah buku pengayaan, buku referensi dan buku panduan pendidikan.

Buku pengayaan dapat dikelompokkan menjadi tiga, yaitu buku pengayaan pengetahuan, buku pengayaan keterampilan dan buku pengayaan kepribadian. Buku pengayaan pengetahuan berfungsi sebagai bacaan peserta didik, pendidik, pengelola pendidikan dan masyarakat lainnya sehingga dapat memperkaya dan meningkatkan penguasaan ilmu pengetahuan dan teknologi (Puskurbuk, 2014).

Margaretha (2016) mengatakan bahwa Provinsi DKI Jakarta memiliki warisan budaya yang indah dan beragam kemudian diperinci lagi oleh Dinas Komunikasi Provinsi DKI Jakarta (2017) menjelaskan bahwa Setu Babakan adalah sebuah kawasan perkampungan yang ditetapkan Pemerintah Provinsi DKI Jakarta sebagai tempat pelestarian dan pengembangan budaya Betawi secara berkesinambungan.

Khoerunnisa dkk., (2016) dalam penelitiannya menyatakan bahwa kurikulum 2013 telah mendorong pembelajaran berbasis budaya agar setiap siswa dapat tanggap akan perkembangan ilmu pengetahuan yang dapat membangun rasa ingin tahu siswa.

Oleh karena itu, penting dilakukan penelitian yang berorientasi etnosains dimensi budaya asli suatu daerah yang dibahas dari ilmu kimia terhadap Kampung Setu Babakan Kota Jakarta guna meningkatkan wawasan pengetahuan siswa terhadap informasi kebudayaan daerah dan meningkatkan motivasi belajar siswa yang diwujudkan dalam sebuah produk buku pengayaan yang bertujuan untuk mengembangkan buku pengayaan 
Pengembangan Buku Pengayaan Kimia Berorientasi Etnosains Kampung Setu Babakan DKI Jakarta

berorientasi etnosains kebudayaan lokal kampung setu babakan DKI Jakarta

\section{METODE PENELITIAN}

Pengembangan ini dilakukan dalam kurun waktu satu tahun yaitu pada bulan Agustus 2017-November 2018. Metode penelitian ini adalah Penelitian dan Pengembangan atau yang biasa dikenal dengan metode Research and Development ( $R$ and $D$ ). $R$ and $D$ adalah metode penelitian yang digunakan untuk menghasilkan suatu produk tertentu, dan menguji keefektifan produk tersebut (Sugiyono, 2006), dalam hal ini yang dikembangkan adalah buku pengayaan kimia berorientasi etnosains. Proses pengembangan buku mengacu model pengembangan ADDIE yang meliputi Analyze (analisis), Design (perancangan), Develop (pengembangan), Implementation (penerapan) \& Evaluate (evaluasi) (Branch, 2009). Penelitian ini dibatasi hanya sampai implementation.

Teknik analisis data yang digunakan pada penelitian ini yaitu analisis deskriptif kuantitatif dan deskriptif kualitatif. Menurut penelitian Rohmah dkk. (2017) analisis deskriptif kuantitatif digunakan untuk menganalisis data berupa skor yang diperoleh dari hasil angket validasi, angket respon guru dan siswa. Metode pengumpulan data dalam penelitian ini terdiri atas; (1) wawancara, (2) validasi, (3) Angket. Data yang diperoleh dari hasil penelitian ini diklasifikasikan menjadi dua kelompok data yaitu data kuantitatif dan data kualitatif.

Teknik analisis data yang digunakan dalam validasi buku pengayaan yaitu skala Guttman dengan pilihan jawaban ya dan tidak. Jawaban dapat berupa skor tertinggi bernilai satu (1) dan skor terendah nol (0) (Riduwan, 2007). Buku pengayaan yang telah divalidasi oleh ahli diberikan kepada 35 siswa dan 4 guru kimia Sekolah Menengah Atas (SMA) di sekitar wilayah Kampung Setu Babakan untuk dilakukan uji coba kelayakan dari penggunaannya. Selanjutnya teknik analisis data yang digunakan untuk mengetahui respon siswa dan guru dalam menentukan kelayakan buku pengayaan yaitu menggunakan skala Likert. Kemudian data yang diperoleh dianalisis dengan menyederhanakan ke dalam bentuk presentase menggunakan rumus berikut(Purwanto, 2009):

$\%$ Kelayakan $=\frac{\text { Skor } \text { total penelitian }}{\text { Skor } \text { maksimal }} \times 100 \%$

\section{HASIL DAN PEMBAHASAN}

Tahap penelitian dan pengembangan model ADDIE yang dilakukan dalam penelitian ini, meliputi tahap analisis, tahap perancangan dan tahap pengembangan. Dari hasil penelitian tiap tahap didapatkan hasil seperti berikut ini.

\subsection{Tahap Analisis}

Tahap analisis didapat hasil kebutuhan melalui wawancara. Asrizal dkk., (2017) dalam penelitiannya melakukan tahap analisis kebutuhan bahan ajar dengan wawancara kepada beberapa guru di sekolah. Hasil wawancara yang diperoleh, guru kimia di sekolah masih menggunakan buku-buku teks pelajaran serta lembar kerja siswa (LKS) lebih lanjut kebudayaan asli Jakarta yang masih kurang dikenal dan diketahui oleh para Masyarakat Jakarta secara umum termasuk di sekitar kawasan Kampung Setu Babakan.

Pada tahap ini diperoleh keterkaitan Kompetensi Inti dan Kompetensi Dasar dengan unsur budaya, hasil identifikasi karakteristik siswa dengan observasi, hasil tujuan instruksional, hasil analisis sumbersumber, merumuskan strategi yang tepat, dan memilih ukuran kertas yaitu $21 \mathrm{~cm} \times 29,7 \mathrm{~cm}$ yang merupakan ukuran kertas A4 dengan alasan untuk memperluas ruang. Pada tahap Jurnal Tadris Kimiya 4, 2 (Desember 2019): 136-146

This is an open access article under CC-BY-SA license (https://creativecommons.org/licenses/by-sa/4.0/) 
Pengembangan Buku Pengayaan Kimia Berorientasi Etnosains Kampung Setu Babakan DKI Jakarta

ini juga dihasilkan schedule untuk menyelesaikan proses pengembangan buku pengayaan kimia agar penelitian berjalan secara terstruktur, rapi, dan konsisten.

\subsection{Tahap Perancangan}

Pada tahap perancangan didapat hasil analisis materi etnosains dengan indikator buku pengayaan. Hasil analisis indikator buku pengayaan yang disusun kemudian dinilai oleh dua orang ahli yaitu ahli pendidikan dan ahli praktisi pendidikan, penilaian dilakukan untuk mengetahui kelemahan materi dan kesesuaian indikator dengan meminta saran dan pendapat ahli. Selanjutnya kelemahan dan saran yang didapat dilengkapi serta diperbaiki untuk menghasilkan buku pengayaan kimia yang lebih baik, untuk kemudian dilakukan perumusan konten. Rumusan konten atau dalam penelitian ini adalah analisis konten isi/materi buku pengayaaan memuat materi-materi serta gambar yang akan dimasukkan ke dalam buku. Pada tahap ini diperoleh penjabaran materi menjadi dua yaitu materi konten kimia dan materi konten etnosains terkait dari indikator berupa ringkasan wacana materi kimia dan etnosains yang relevan.

Berdasarkan Tabel 1, dapat dijelaskan:

\subsubsection{Gabus Pucung}

Gabus pucung selalu ada saat perayaan acara adat betawi seperti khitanan, maulid dan akikah. Gabus pucung terbuat dari ikan gabus dan kuah hitam pekat berasal dari buah kluwak dengan penjelasan ilmiah yaitu buah kluwak mentah (yang belum diolah) mempunyai racun sianida dalam konsentrasi yang tinggi, beberapa kandungan kimia lainnya yang terdapat pada buah kluwak antara lain vitamin $\mathrm{C}$, ion besi, betakaroten, asam hidnokarpat, asam khaulmograt, asam glorat, dan tanin. Sehingga materi kimia terkait yaitu koloid dengan kuah hitam pekat, makromolekul dengan kandungan buah

kluwak, asam dan basa dengan jeruk nipis penghilang amis pada ikan gabus yakni kandungan senyawa amino Trimetilamin oksida (TMAO) pada ikan dan kandungan asam askorbat pada jeruk nipis yang mencampurkan kedua senyawa tersebut akan menetralkannya sehingga terjadi proses asam basa.

Tabel 1. Hasil Keterkaitan Etnosains dan Materi Kimia

\begin{tabular}{|c|c|c|}
\hline No & Etnosains & Materi Kimia \\
\hline \multicolumn{3}{|c|}{ Gabus Pucung } \\
\hline 1. & Kuah hitam pekat & Koloid \\
\hline 2. & $\begin{array}{l}\text { Jeruk nipis } \\
\text { penghilang amis }\end{array}$ & Asam dan basa \\
\hline 3. & Kandungan Kluwak & Makromolekul \\
\hline 4. & Pewarna makanan & Koloid \\
\hline \multicolumn{3}{|c|}{$\begin{array}{c}\text { Batik Betawi } \\
\end{array}$} \\
\hline 1. & $\begin{array}{l}\text { Senyawa kimia } \\
\text { pada kain }\end{array}$ & Polimer \\
\hline 2. & $\begin{array}{l}\text { Penyerapan warna } \\
\text { pada kain }\end{array}$ & Ikatan kimia \\
\hline 3. & $\begin{array}{l}\text { Perebusan kain } \\
\text { dengan kanji/soda } \\
\text { ash }\end{array}$ & Asam dan basa \\
\hline \multicolumn{3}{|c|}{ Kerak Telor } \\
\hline 1. & Arang & Hidrokarbon \\
\hline 2. & $\begin{array}{l}\text { Kerak hitam di } \\
\text { makanan }\end{array}$ & Makromolekul \\
\hline 3. & $\begin{array}{l}\text { Pengasapan } \\
\text { makanan }\end{array}$ & Hidrokarbon \\
\hline \multicolumn{3}{|c|}{ Asinan Betawi } \\
\hline 1. & Penggunakan cuka & sam dan basa \\
\hline 2. & Kuah makanan & \begin{tabular}{|l} 
Sifat koligati \\
larutan
\end{tabular} \\
\hline \multicolumn{3}{|c|}{ Roti Buaya } \\
\hline 1. & Proses fermentasi & Makromolekul \\
\hline 2. & $\begin{array}{l}\text { Proses } \\
\text { pengembangan } \\
\text { makanan }\end{array}$ & Koloid \\
\hline 3. & $\begin{array}{l}\text { Pencampuran } \\
\text { bahan makanan }\end{array}$ & Ikatan Kimia \\
\hline \multicolumn{3}{|c|}{ Petasan } \\
\hline 1. & Ledakan petasan & Redoks \\
\hline 2. & $\begin{array}{l}\text { Serbuk } \\
\text { petasan }\end{array}$ & Makromolekul \\
\hline
\end{tabular}

Jurnal Tadris Kimiya 4, 2 (Desember 2019): 136-146

This is an open access article under CC-BY-SA license (https://creativecommons.org/licenses/by-sa/4.0/) 
Pengembangan Buku Pengayaan Kimia Berorientasi Etnosains Kampung Setu Babakan DKI Jakarta

\subsubsection{Batik Betawi}

Batik betawi merupakan kain katun dengan motif khas Jakarta diantaranya ondel-ondel, tumpal dan gigi balang. Penjelasan ilmiahnya yaitu kandungan lilin batik untuk mewarnai batik ialah naphtol dan indigosol. Selain itu kandungan kimia pada kain batik adalah nilon dan poliester yang termasuk polimer. Kemudian ikatan kimia didapat dengan proses penyerapan warna kain dan asam basa pada perebusan kain.

\subsubsection{Kerak Telor}

Kerak telor merupakan makanan tradisional yang dimasak menggunakan arang dan tungku. Penjelasan ilmiahnya yaitu kandungan bahan kimia arang kayu adalah karbon dan kandungan bahan kimia beras ketan putih mengandung fosfor dan zat besi. Pada proses memasak kerak telor, berlangsung pembakaran secara bertingkat. Makromolekul dengan senyawa penyebab kerak hitam yaitu kerak hitam yang muncul akibat adanya pembakaran unsur karbon yang terkandung dalam telur yaitu protein dan lemak.

\subsubsection{Asinan Betawi}

Asinan betawi merupakan makanan yang terbuat dari sayur dan buah-buahan mentah dengan bumbu kacang. Adapun penjelasan ilmiahnya yaitu pemberian cuka yang mampu meberikan rasa dan aroma asam pada makanan, kandungan asam asetat glasial. Materi kimia terkait yaitu asam basa dengan penggunaan cuka pada asinan, dan sifat koligatif larutan dengan kuah asinan yaitu peristiwa reaksi kimia yang terjadi dalam asinan melibatkan sifat koligatif larutan yaitu proses tekanan osmosis yakni peristiwa perpindahan cairan yang encer ke cairan yang lebih pekat melewati membrane, sehingga menyebabkan asinan yang didiamkan beberapa menit memiliki citarasa yang lebih segar.

\subsubsection{Roti Buaya}

merupakan bentuk roti seperti buaya yang melambangkan kesetiaan, sehingga selalu ada saat pernikahan adat budaya Jakarta, dengan penjelasan ilmiah yaitu salah satu bahan adonan roti adalah natrium bikarbonat (baking soda) yang memiliki rumus $\mathrm{NaHCO}_{3}$, kemudian baking soda melepaskan gas karbon dioksida $\left(\mathrm{CO}_{2}\right)$ dengan cepat yang berada dalam kontak dengan larutan asam, gelembung gas dilepaskan dalam adonan kental dan kemudian memperluas karena panas dari oven. Setelah adonan mengeras gelembung terperangkap sehingga menghasilkan roti besar namun ringan. Materi kimia terkait yaitu makromolekul dengan fermentasi roti, koloid dengan pengembangan volume roti, dan ikatan kimia dengan pencampuran adonan roti.

\subsubsection{Petasan}

merupakan alat peledak ringan yang digunakan untuk perayaan pernikahan adat masyarakat asli Jakarta dengan tujuan memberi kabar dan sebagai wujud kegembiraan. Penjelasan ilmiahnya yaitu petasan atau mercon mengandung kalium klorat dan belerang. Materi kimia terkait yaitu redoks dengan ledakan petasan, dan makromolekul dengan serbuk kimia dalam petasan yakni mineral magnetit $\left(\mathrm{Fe}_{3} \mathrm{O}_{4}\right)$, serbuk arang kayu, Belerang (S), dan Kalium Nitrat $\left(\mathrm{KNO}_{3}\right)$.

\subsection{Tahap Pengembangan}

Pada tahap ini dilakukan penyusunan dan validasi buku pengayaan. Buku pengayaan didesain menggunakan aplikasi Microsoft Office Publisher dan Paint. Pada buku pengayaan memuat bagian buku meliputi bagian awal buku, bagian materi atau isi dan bagian akhir buku (Puskurbuk, 2014). Dalam mengembangkan dan menggunakan etnosains sebagai peluas wawasan siswa, maka buku ini mengacu pada salah satu Jurnal Tadris Kimiya 4, 2 (Desember 2019): 136-146

This is an open access article under CC-BY-SA license (https://creativecommons.org/licenses/by-sa/4.0/) 
Pengembangan Buku Pengayaan Kimia Berorientasi Etnosains Kampung Setu Babakan DKI Jakarta

dimensi etnosains yaitu memusatkan pada validator ahli materi yang telah disebutkan di kebudayaan (Sudarmin, 2014).

Buku yang telah disusun, selanjutnya dilakukan validasi oleh tiga orang ahli yaitu satu orang ahli materi, satu orang ahli media, dan satu orang ahli praktisi pendidikan. Pada tahap validasi, peneliti melakukan beberapa perbaikan sesuai saran dari ahli. Zunaidah \& Amin (2016) menyatakan bahwa perbaikan didasarkan pada saran dan masukan dari

bagian penyajian data, maupun saran secara lisan pada saat diskusi dengan ahli.

Kelayakan buku pengayaan kimia berorientasi etnosains yang dikembangkan berasal dari instrumen penilaian menurut Pusat Kurikulum dan Perbukuan (Puskurbuk). Hasil penilaian validasi ahli dapat dilihat pada Tabel. 2.

Tabel 2. Hasil Validasi Buku Pengayaan

\begin{tabular}{|c|l|l|l|l|}
\hline \multirow{2}{*}{ Validator } & \multicolumn{2}{c|}{ Validasi I } & \multicolumn{2}{c|}{ Validasi II } \\
\cline { 2 - 5 } & Rerata & Kriteria & Rerata & Kriteria \\
\hline 1 (ahli materi) & $82,35 \%$ & Sangat Baik & $100 \%$ & Sangat Baik \\
\hline 2 (ahli media) & $88 \%$ & Sangat Baik & $88 \%$ & Sangat Baik \\
\hline 3 (prakti-si pendi-dikan) & $97,10 \%$ & Sangat Baik & $100 \%$ & Sangat Baik \\
\hline Rata-rata & $89,15 \%$ & Sangat Baik & $96,00 \%$ & Sangat Baik \\
\hline
\end{tabular}

Berdasarkan Tabel 2 didapatkan hasil ratarata dari tiga validator, pada validasi pertama mendapatkan rata-rata sebesar $89,15 \%$ dan validasi kedua mendapatkan rata-rata sebesar $96,00 \%$. Setelah dilakukan validasi oleh validator, tahap selanjutnya adalah merevisi beberapa aspek buku berdasarkan masukan dan saran dari validator yang bersifat membangun dan saling melengkapi. Berikut daftar komentar dan saran dari ahli selama kegiatan validasi dilakukan dapat dilihat pada Tabel 3.

Tabel 3. Komentar dan Saran Validator

\begin{tabular}{|l|l|}
\hline No & \multicolumn{1}{|c|}{ Komentar dan Saran } \\
\hline 1. & $\begin{array}{l}\text { gambar kebudayaan perjelas, kurang } \\
\text { menonjol }\end{array}$ \\
\hline 2. & $\begin{array}{l}\text { Pengecekan kembali ejaan serta } \\
\text { perbaikan grafis }\end{array}$ \\
\hline 3. & Ukuran buku diperbesar \\
\hline 4. & Ukuran huruf diperbesar \\
\hline 5. & Gambar diperjelas \\
\hline 6. & Lihat buku-buku kimia dari luar negeri \\
\hline
\end{tabular}

Berdasarkan Tabel 3, setelah mendapat saran dan komentar saat validasi, peneliti melakukan perubahan sesuai dengan arahan validator, diantaranya seperti berikut.

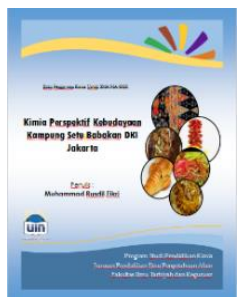

(a)

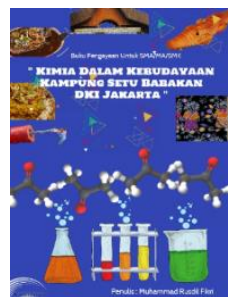

(b)
Gambar 1. (a) Cover Depan Sebelum Revisi; (b) Cover Depan Setelah Revisi

Sebagaimana Gambar 1 pada bagian cover buku terdapat perubahan untuk judul buku pengayaan yang menurut validator judul yang baik harus sederhana tapi mempunyai arti yang mendalam dan gambar cover yang harus mewakili isi buku.

Pada aspek grafis terdapat bagian isi buku pada beberapa materi yang terlalu memiliki ruang kosong serta materi "Si Kluwak Penyebab Hitam Pekat" yang belum lengkap. 


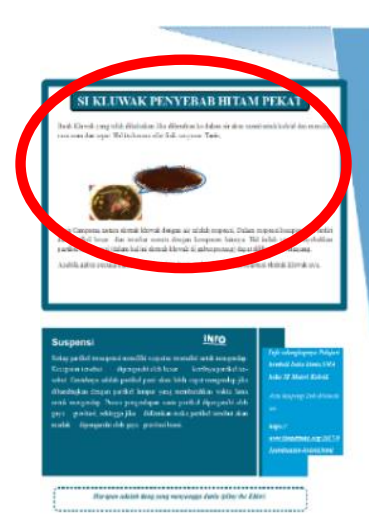

(a)

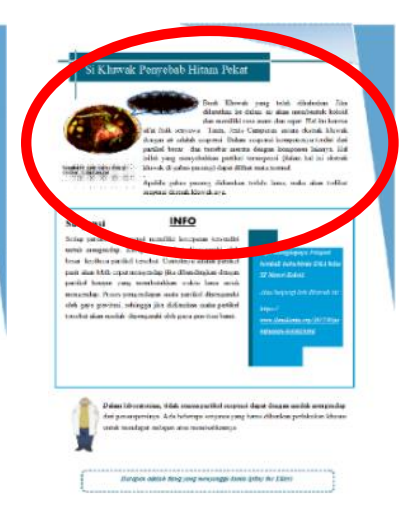

(b)
Gambar 2. Perubahan Aspek Grafis (a) Sebelum Revisi (b) Setelah Revisi

\subsection{Tahap Implementasi}

Tahap ini bertujuan mengetahui respon siswa dan guru terhadap buku pengayaan kimia berorientasi etnosains sebagai buku pendamping buku teks yang dapat menambah wawasan dan pengetahuan pembaca. Pada tahap ini dilakukan melalui uji coba terbatas kepada 36 orang siswa kelas XII MIPA 4 di SMAN 38 Jakarta dan 4 orang guru kimia dengan rincian 2 orang guru kimia SMAN 38 Jakarta dan 2 orang guru kimia di SMAN 49 Jakarta.

Kelayakan buku pengayaan ditetapkan berdasarkan hasil penilaian dari setiap komponen yang dinilai, yaitu kelayakan materi, penyajian, Bahasa, dan kegrafisan (Pusat Kurikulum dan Perbukuan, 2014). Hasil tanggapan respon guru dan siswa dapat dilihat pada Tabel 4 dan 5 .

Tabel 4. Persentase rata-rata hasil angket respon guru

\begin{tabular}{|l|l|l|l|}
\hline No. & Aspek & $\begin{array}{l}\text { Rata- } \\
\text { rata }\end{array}$ & Kriteria \\
\hline 1. & Materi & $91,25 \%$ & $\begin{array}{l}\text { Sangat } \\
\text { Baik }\end{array}$ \\
\hline 2. & Penyajian & $80,00 \%$ & Baik \\
\hline 3. & Bahasa & $87,50 \%$ & $\begin{array}{l}\text { Sangat } \\
\text { Baik }\end{array}$ \\
\hline
\end{tabular}

\begin{tabular}{|l|l|l|l|}
\hline 4. & Kegrafisan & $88,00 \%$ & $\begin{array}{l}\text { Sangat } \\
\text { Baik }\end{array}$ \\
\hline \multicolumn{2}{|c|}{ Rata-rata } & $87,00 \%$ & $\begin{array}{l}\text { Sangat } \\
\text { Baik }\end{array}$ \\
\hline
\end{tabular}

Berdasarkan Tabel 4, dapat dilihat bahwa urutan respon guru tertinggi yaitu pada aspek materi dengan persentase $91,25 \%$. Hal ini menunjukkan bahwa secara umum aspek materi dalam buku pengayaan tergolong sangat baik. Hal tersebut didukung oleh Suwarni (2015) yang menyatakan bahwa buku ajar memiliki prinsip keajegan, sistematis dan mengaitkannya dengan perkembangan ilmu terkini.

Urutan tertinggi kedua yaitu aspek kegrafisan dengan persentase $88 \%$. Hal ini menunjukkan bahwa pada aspek kegrafisan, buku di desain dengan kulit buku yang memiliki nilai estetika, isi buku didesain dengan jenis dan ukuran huruf yang konsisten dan memiliki tingkat keterbacaan tinggi, serta penempatan yang proporsional antara isi dengan ilustrasi.

Urutan tertinggi ketiga yaitu aspek bahasa dengan persentase $87,50 \%$. Hal ini menunjukkan bahwa bahasa yang digunakan dalam buku pengayaan ini sudah sesuai Ejaan Yang Disempurnakan karena menurut Jannah dan Dwiningsih (2013) dalam penelitiannya menyatakan bahwa kategori layak pada aspek bahasa didapatkan karena bahasa yang digunakan dalam buku yang dikembangkan merupakan bahasa yang baik dan benar sesuai dengan kaidah Bahasa Indonesia yang baku.

Pada aspek penyajian mendapatkan nilai terendah dengan persentase $80 \%$ dengan kategori baik. Hal ini bermakna bahwa penyajian materi, baik teks maupun gambar disesuaikan dengan usia siswa SMA serta dengan penyajian yang dibuat menarik sehingga dapat memotivasi siswa untuk

Jurnal Tadris Kimiya 4, 2 (Desember 2019): 136-146

This is an open access article under CC-BY-SA license (https://creativecommons.org/licenses/by-sa/4.0/) 
Pengembangan Buku Pengayaan Kimia Berorientasi Etnosains Kampung Setu Babakan DKI Jakarta

membaca lebih lanjut. Rata-rata persentase keseluruhan yaitu sebesar $87 \%$ termasuk dalam kategori sangat baik.

Tabel 5. Persentase rata-rata hasil angket respon siswa

\begin{tabular}{|c|c|c|c|}
\hline No. & Aspek & $\begin{array}{l}\text { Rata- } \\
\text { rata }\end{array}$ & Kriteria \\
\hline 1. & Materi & $86,88 \%$ & $\begin{array}{l}\text { Sangat } \\
\text { Baik }\end{array}$ \\
\hline 2. & Penyajian & $82,42 \%$ & $\begin{array}{l}\text { Sangat } \\
\text { Baik }\end{array}$ \\
\hline 3. & Bahasa & $84,71 \%$ & $\begin{array}{l}\text { Sangat } \\
\text { Baik } \\
\end{array}$ \\
\hline 4. & Kegrafisan & $83,53 \%$ & $\begin{array}{l}\text { Sangat } \\
\text { Baik }\end{array}$ \\
\hline \multicolumn{2}{|c|}{ Rata-rata } & $84,20 \%$ & $\begin{array}{l}\text { Sangat } \\
\text { Baik }\end{array}$ \\
\hline
\end{tabular}

Berdasarkan Tabel 4, dapat dilihat bahwa urutan respon guru tertinggi yaitu pada aspek materi dengan persentase $86,88 \%$ yang menunjukkan bahwa secara umum aspek materi dalam buku pengayaan tergolong sangat baik. Namun, materi kimia yang dibahas pada buku pengayaan ini cukup banyak tetapi hanya secara singkat, oleh sebab itu masih ada beberapa siswa yang merasa kebingungan. Prasetiyo \& Perwanitingtyas (2017) menjelaskan bahwa materi tidak boleh terlalu sedikit dan tidak boleh terlalu banyak. Jika terlalu sedikit maka kurang membantu mencapai kompetensi dan jika terlalu banyak maka tidak efektif.

Urutan tertinggi kedua yaitu aspek bahasa dengan persentase $84,71 \%$. Hal tersebut menandakan bahwa bahasa yang digunakan dalam buku pengayaan ini sederhana, lugas, sesuai EYD serta komunikatif.

Selanjutnya urutan ketiga yaitu aspek kegrafisan dengan persentase $83,53 \%$ yang menunjukkan bahwa buku pengayaan ini memiliki ilustrasi (gambar) yang berwarna dan menarik sehingga membuat siswa tertarik untuk membaca buku pengayaan dan keterangan ilustrasi (gambar) sesuai dengan gambar yang disajikan, hal ini sesuai dengan penelitian Istiningrum dkk. (2016) yang menjelaskan bahwa desain sampul buku ajar harus proporsional, desain isi buku ajar harus menarik, gambar dan warna yang membuat siswa kurang jelas untuk membacanya harus diubah agar menarik minat siswa. Selanjutnya pada aspek penyajian dengan persentase $82,42 \%$ hal ini menunjukkan bahwa penyajian gambar dan materi pada buku pengayaan ini sudah sangat baik. hal ini menunjukkan bahwa buku pengayaan yang dikembangkan memiliki karakter user friendly, karena menurut Widodo dan Jasmadi (2008) bahan ajar yang memiliki karakter user friendly secara umum pengorganisasian antara isi/materi dan ilustrasinya (seperti gambar) ditujukan untuk kemudahan peserta didik ketika memanfaatkannya.

\section{KESIMPULAN}

Dihasilkan buku pengayaan kimia berorientasi etnosains Kampung Setu Babakan DKI Jakarta yang dikembangkan melalui model ADDIE, terdiri dari analyze, design, development, implement, dan evaluate yang kemudian dinilai dan divalidasi sebanyak dua kali oleh satu orang dosen sebagai ahli materi, satu orang dosen sebagai ahli media, dan satu orang guru kimia sebagai praktisi pendidikan. Dihasilkan rata-rata persentase validasi pertama masingmasing $82,35 \%$, 88\% dan 97,10\% kemudian validasi kedua masing-masing 100\%, $88 \%$ dan $100 \%$. Selanjutnya buku pengayaan dinilai oleh guru dan siswa melalui uji coba terbatas kepada 36 orang siswa kelas XII MIPA 4 di SMAN 38 Jakarta dan dua orang guru mata pelajaran kimia di SMAN 38 Jakarta dan dua orang guru kimia di SMAN 49 Jakarta kemudian diperoleh rata-rata persentase penilaian sebesar $87 \%$ untuk respon guru dan $84,20 \%$ untuk respon siswa dengan kategori sangat baik.

Jurnal Tadris Kimiya 4, 2 (Desember 2019): 136-146

This is an open access article under CC-BY-SA license (https://creativecommons.org/licenses/by-sa/4.0/) 
Pengembangan Buku Pengayaan Kimia Berorientasi Etnosains Kampung Setu Babakan DKI Jakarta

\section{DAFTAR PUSTAKA}

Asrizal, Festiyed, Sumarmin. (2017). Analisis Kebutuhan Pengembangan Bahan Ajar IPA Terpadu Bermuatan Literasi Era Digital Untuk Pembelajaran Siswa SMP Kelas VIII. Jurnal Eksakta Pendidikan. 1(1), 4.

Battiste, Marie. (2005). Indigenous Knowledge: Foundations For First Nations. WINHEC Journal. 3.

Branch, Robert Marie. (2009). Instructional Design: The ADDIE Approach. USA: Springher Dordrecht Heidelberg London

Dinas Komunikasi Provinsi DKI Jakarta. "Profil Kampung Setu Babakan", www.jakarta.go.id/web/encyclopedi a, diakses pada tanggal 10 September 2017.

Istiningrum, Amin \& Lestari. (2016). Pengembangan Buku Ajar Biologi Sel Berbasis Bioinformatika. Jurnal pendidikan. 1(9), 3

Jannah \& Dwiningsih. (2013). Kelayakan Buku Ajar Kimia Berorientasi Quantum Learning Pada Materi Pokok Kimia Unsur Untuk Siswa Kelas XII SMA. JurnalPendidikanKimia. 2(2), 5

Kartono, Hairida, \& Gusti Bujang. (2010). Penelusuran Budaya dan Teknologi Lokal Dalam Rangka Rekonstruksi dsan Pengembangan Sains di Sekolah Dasar. Jurnal Cakrawala Pendidikan. 7(2): 1
Khoerunnisa, Murbangun, \& Sudarmin. (2016). Pengembangan Modul IPA Terpadu Etnosains Untuk Menumbuhkan Minat Kewirausahaan. Journal of Innovative Science Education. 5(1), 45,52 .

Margaretha. (2016). Bahasa dan Budaya Indonesia. Jakarta: Mustika Pustaka Negeri.

Peraturan Menteri Pendidikan dan Kebudayaa Nomor 8 Tahun 2016 tentang Buku Yang Digunakan Oleh Satuan Pendidikan.

Prasetiyo, N. A., \& Perwiraningtyas, P. (2017). Pengembangan Buku Ajar Berbasis Lingkungan Hidup pada Mata Kuliah Biologi di Universitas Tribuwana Tunggadewi. Jurnal Pendidikan Biologi Indonesia, 3(1), 25

Purwanto, Ngalim. (2009). Prinsip-Prinsip dan Teknik Evaluasi Pengajaran. Bandung: Remaja Rosda Karya.

Puskurbuk. (2014). Pedoman Penilaian Buku Nonteks. Jakarta : Depdiknas.

Rahmawati, Yuli \& Ahmad Ridwan. (2017). Empowering Students Chemistry Learning: The Integration of Ethnochemistry in Culturally Resohmah,ponsive Teaching. Bulgarian Journal of Science Education. 26(6), 815.

Riduwan. (2007). Skala Pengukuran Variabelvariabel penelitian. Bandung: Alfabeta.

Jurnal Tadris Kimiya 4, 2 (Desember 2019): 136-146 
Rohmah, Hariyono \& Sudarmiatin. (2017). Pengembangan Buku Ajar IPS SD Berbasis Kontekstual. Jurnal Pendidikan, 2(5), 719,721.

Shidiq, A. S. (2016). Pembelajaran Sains Kimia Berbasis Etnosains untuk Meningkatkan Minat dan Prestasi Belajar Siswa. In Prosiding Seminar Nasional Kimia dan Pendidikan Kimia VIII.

Suastra, I Wayan. (2006). Perspektif Kultural Pendidikan Sains, Belajar Sebagai Proses Inkulturasi. Jurnal Pendidikan dan Pengajaran, 39(3), 451,452

Sudarmin. (2014). Pendidikan Karakter, Etnosains dan Kearifan Lokal (Konsep dan Penerapannya dalam Penelitian dan Pembelajaran Sains).Semarang : Fakultas MIPA Universitas Negeri Semarang.

Sugiyono. (2006). Metode Penelitian Kuantitatif, Kualitatif, dan $R \& D$. Bandung: Alfabeta.

Suwarni, Erna. (2015). Pengembangan Buku Ajar Berbasis Lokal Materi Keanekaragaman Laba-laba di Kota Metro Sebagai Sumber Belajar Alternatif Biologi untuk Siswa SMA Kelas X. Jurnal Pendidikan Biologi. 6(2), 90

Toharudin, dkk. (2011). Membangun Literasi Sains Peserta Didik. Bandung: Humaniora.

Widodo, C. S \& Jasmadi. (2008). Panduan Menyusun Bahan Ajar Berbasis
Kompetensi. Jakarta: PT Elex Media Komputindo.

Zunaidah \& Amin. (2016). Pengembangan Bahan Ajar Matakuliah Bioteknologi Berdasarkan Kebutuhan dan Karakter Mahasiswa Univesitas Nusantara PGRI Kediri. Jurnal Pendidikan Biologi Indonesia. 2(1), 24. 